\title{
О РОЛИ ОРГАНОВ ПРОКУРАТУРЫ В РЕАЛИЗАЦИИ СТАТЬИ 29.2 ФЕДЕРАЛЬНОГО ЗАКОНА «ОБ ОБЩИХ ПРИНЦИПАХ ОРГАНИЗАЦИИ ЗАКОНОДАТЕЛЬНЫХ (ПРЕДСТАВИТЕЛЬНЫХ) И ИСПОЛНИТЕЛЬНЫХ ОРГАНОВ ГОСУДАРСТВЕННОЙ ВЛАСТИ СУБЪЕКТОВ РОССИЙСКОЙ ФЕДЕРАЦИИ॥
}

Аннотация. Предметом исследования в настоящей статье являются положения статьи 29.2 Федерального закона "Об общих принципах организации законодательных (представительных) и исполнительных органов государственной власти субъектов Российской Федерации", определившие процедуру проведения плановых и внеплановых проверок органов государственной власти субъектов Российской Федерации и должностных лиц этих органов. Автор рассматривает вопрос с точки зрения участия органов прокуратуры в процессе регулирования средствами прокурорского надзора и иными полномочиями контрольнонадзорной деятельности в рассматриваемой сфере В основе исследования лежит метод сравнения с положениями ранее принятых и апробированных практикой законодательных норм, выявление коллизионных аспектов рассматриваемой новеллы и прогнозирование сопутствующих этому проблем в правоприменении Основными выводами проведенного исследования является, с одной стороны, одобрение автором восполнения законодателем правового пробела в регулировании вопросов контрольно-надзорной деятельности применительно к органам государственной власти субъектов Российской Федерации и должностным лицам таких органов, а с другой - наличие явных коллизий в исследуемых новеллах. В контексте прокурорской деятельности вопрос исследуется впервые.

Ключевые слова: внеплановая проверка, государственный учет, государственный контроль (надзор), должностное лицо, орган государственной власти, прокурор, прокурорский надзор, разграничение компетенции, реестр проверок, согласование проведения проверки.

Abstract. The research subject is the provisions of the article 29.2 of the Federal Law "On the general principles of organization of legislative (representative) and executive authorities of constituent territories of the Russian Federation", which have defined the procedure of scheduled and unscheduled inspections of regional public authorities and their officials in the Russian Federation. The author considers the issue from the position of prosecution agencies' participation in the process of regulation of supervision activities in this sphere by means of prosecutor's supervision and other authorities. The research is based on the method of comparison with the provisions of the previously adopted and approved legislative provisions, the detection of contentious aspects of this legislative novel, and the prognostication of the related law enforcement problems. The author, on the one hand, approves the filling of the legislative gap in the regulation of the issues of supervision activity in relation to the local authorities and their officials, and on the other hand, detects the obvious collisions in the novels under consideration. This issue hasn't been studied in the context of prosecutor's activity so far.

Key words: distribution of powers, prosecutor's supervision, prosecutor, public authority, official, government supervision (control), state recording, unscheduled inspection, register of inspections, schedule the inspection.

15 июля 2016 г. вступили в силу новеллы [1], дополнившие Федеральный закон от 06.10.1999 № 184-Ф3 «Об общих принципах организации законодательных (представительных) и исполнительных органов государственной власти субъектов Российской Федерации» (далее - Закон № 184-Ф3) [2] статьей 29.2, регламентирующей вопросы государственного контроля (надзора) за деятельностью органов государственной власти субъектов Российской Федерации и должностных лиц указанных органов. Как следует из пояснительной записки, прилагавшейся к разрабо- танному законопроекту, получившему в последующем № 923490-6, документ имел направленность на установление единого подхода к осуществлению государственного контроля (надзора) за деятельностью органов государственной власти субъектов Российской Федерации и должностных лиц таких органов [3]. Тем самым предусматривалось в определенном смысле закрыть вопрос с законодательным регулированием контрольно-надзорной деятельности, которая ранее была упорядочена в отношении субъектов предпринимательской деятельности [4], а также органов местного само- 
управления и должностных лиц местного самоуправления [5]. Важная роль в Законе № 184-ФЗ отводится органам прокуратуры, которые, начиная с 2009 г. Законом № 294-ФЗ наделены особым статусом, предусматривающим в рамках осуществления надзора за исполнением законов органами контроля (надзора) применение полномочий по согласованию проводимых этими органами внеплановых выездных проверок либо отказу в их согласовании, а с 1 января 2014 г. в силу ч. 2.2 ст. 77 Закона № 131-Ф3 официально являются координаторами деятельности органов государственного контроля (надзора) по планированию и проведению проверок в отношении органов и должностных лиц местного самоуправления [6].

С учетом апробированного к настоящему времени практикой опыта применения осуществления прокурорами «согласовательного» надзора законодатель в статье 29.2 Закона № 184-Ф3 пошел по пути вполне определенных аналогий со статьей 77 Закона № 131-Ф3.

Давая характеристику рассматриваемой новелле, полагаем необходимым обратить внимание на закрепленный в части 1 статьи 29.2 предмет прокурорского надзора, который составляют соблюдение Конституции Российской Федерации, исполнение федеральных конституционных законов, федеральных законов, конституций (уставов), законов субъектов Российской Федерации органами государственной власти субъектов Российской Федерации и должностными лицами органов государственной власти субъектов Российской Федерации, а также соответствие законам издаваемых ими правовых актов. То есть, если сравнивать его с «классическим» предметом надзора за исполнением законов, закрепленным в статье 21 Федерального закона от 17.01.1992 № 2202-1 «О прокуратуре Российской Федерации» (далее - Закон о прокуратуре) [7], то «лишним» звеном, дополняющим базовое представление о предмете надзора, выступает исполнение указанными органами и лицами конституций (уставов) соответствующих субъектов Российской Федерации, которые, несмотря на позиционирование их во многих регионах в качестве «основных законов», собственно законами, подобно Конституции России, не являются.

Вместе с тем именно наличие в анализируемой формулировке статутных актов позволяет упрекнуть законодателя в определенной некорректности, поскольку вторая часть предмета надзорной деятельности прокуроров, касающаяся надзора за законностью правовых актов, с одной стороны, дословно корреспондирует все той же статье 21 Закона о прокуратуре, а с другой - не учитывает закрепленную в пункте 1 статьи 27 Закона № 184-Ф3 норму, наделяющую прокурора субъекта Россий- ской Федерации (его заместителя) правом опротестовывать правовые акты региональных органов и должностных лиц, противоречащие Конституции Российской Федерации, федеральным законам, конституции (уставу) и законам субъекта Российской Федерации. То есть за рамками опять-таки «классического» представления о рассматриваемой составляющей предмета надзора за исполнением законов выступают Конституция Российской Федерации и региональные конституции (уставы). На это обстоятельство ранее мы уже обращали внимание в одной из своих статей [8], подчеркивая проблематичность оспаривания правовых актов, не соответствующих названным статутным документам.

Еще один вопрос коллизионного характера, который является более проблематичным, связан с разграничением компетенции органов прокуратуры и органов государственного контроля (надзора), что позволяет провести вполне определенные аналогии со статьей 77 Закона № 131-Ф3, на что ранее нами также обращалось внимание [9]. В чем же видятся проблемы, вытекающие из анализа содержания части 2 статьи 29.2 Закона № 184-Ф3?

Как следует из указанной нормы, соответствующие органы государственного контроля (надзора), включая территориальные органы федеральных органов исполнительной власти, осуществляют в пределах своей компетенции контроль (надзор) за исполнением органами государственной власти субъектов Российской Федерации и должностными лицами таких органов Конституции Российской Федерации, федеральных конституционных законов, федеральных законов и иных нормативных правовых актов Российской Федерации, конституций (уставов), законов и иных нормативных правовых актов субъектов Российской Федерации при осуществлении ими соответствующих полномочий, в том числе полномочий Российской Федерации, переданных для осуществления органам государственной власти субъектов Российской Федерации, а также за соответствием правовых актов субъектов Российской Федерации требованиям Конституции Российской Федерации, федеральных конституционных законов, федеральных законов и иных нормативных правовых актов Российской Федерации, конституций (уставов) субъектов Российской Федерации. То есть в выделенных нами фрагментах компетенция органов прокуратуры и контрольно-надзорных органов пересекается. При этом вызывает сомнение вопрос о возможности проверки органами контроля (надзора) соответствия правовых актов подконтрольных им объектов и субъектов Конституции Российской Федерации (единственным, причем весьма сомнительным исключением, является подпункт «б» пункта 7 Правил отмены правовых актов 


\section{Административное и муниципальное право 11 (107) • 2016}

исполнительной власти субъектов Российской Федерации, осуществляющих переданные полномочия Российской Федерации в области лесных отношений, утвержденных постановлением Правительства Российской Федерации от 29.06.2011 № 524 [10]), а равно федеральным конституционным законам. Что касается включения в предмет контрольно-надзорной деятельности исполнения Конституции Российской Федерации, то аналогичная формулировка содержится также в части 2 статьи 77 Закона № 131-Ф3, подробную характеристику которой мы дали в упомянутой выше статье.

Частью 3 статьи 29.2 Закона № 184-ФЗ определено, что координацию деятельности органов государственного контроля (надзора) по планированию и проведению проверок деятельности органов государственной власти субъектов Российской Федерации и должностных лиц таких органов осуществляют органы прокуратуры. Эта норма с учетом поправки на объекты и субъекты контрольно-надзорной деятельности является дословным «слепком» с части 2.2 статьи 77 Закона № 131-Ф3, равно как элемент заимствования имеет место и в положении о недопустимости дублирования при осуществлении государственного контроля (надзора) полномочий соответствующих органов, в связи с чем хотелось бы подчеркнуть явную некорректность формулировки. Ведь очевидно, что полномочиями конкретные органы, а если быть точными, то их должностные лица, наделяются федеральными законами, а также нормативными правовыми актами главы государства и Правительства Российской Федерации. В этом смысле, полномочия могут дублироваться исключительно в подобных актах (хотя с самого начала административной реформы в 2004 году основные усилия реформаторов были направлены на устранение такого дублирования), но никак не в правоприменительной деятельности тех или иных органов. Очевидно, на недопущение проявления недоработок административной реформы на практике и направлено позиционирование органов прокуратуры в качестве координаторов.

С точки зрения теории прокурорских функций немаловажным является вопрос о месте подобной «диспетчерской» работы в системе внешнефункциональной деятельности органов прокуратуры. Как было отмечено выше, координация деятельности контрольно-надзорных органов относится к вопросам планирования и проведения ими проверок. В силу части 4 статьи 29.2 Закона № 184-ФЗ органы прокуратуры принимают непосредственное участие в формировании ежегодных планов проверок посредством тщательной проверки и «отбраковывания» не отвечающих требованиям закона мероприятий. В свое время на примере статьи 9 Зако- на № 294-Ф3, закрепляющей схожие вопросы, мы отнесли подобную деятельность к такому участку внешнефункциональной деятельности прокуратуры как «государственный учет» [11] на основании того, что речь идет об аккумулировании именно в прокуратуре определенного объема сведений, доступных в последующем широкому кругу потенциальных пользователей. Как и в случае со статьей 77 Закона № 131-Ф3, часть 4 статьи 29.2 Закона № 184ФЗ предусматривает совместное проведение плановых проверок органами государственно контроля (надзора), что обусловливает необходимость учета интересов каждого из органов контроля (надзора) при консолидации их усилий в единое проверочное мероприятие. Законодатель определяет, что ежегодный сводный план проверок формируется Генеральной прокуратурой Российской Федерации на основании ежегодных планов проверок по субъектам Российской Федерации, сформированных прокуратурами субъектов Российской Федерации. Это в целом подтверждает соответствующий статус Генеральной прокуратуры Российской Федерации, определенной в статье 9 Закона № 294-Ф3 в качестве единого депозитария информации о плановых проверочных мероприятий, аккумулирующего соответствующие сведения, поступающие из прокуратур регионального звена.

Как и в случае со статьей 77 Закона № 131-Ф3, прокуратуры субъектов Российской Федерации по результатам изучения проектов планов проверок помимо исключения не соответствующих требованиям закона проверочных мероприятий вправе вносить руководителям органов контроля (надзора) предложения о проведении совместных проверок. Однако здесь имеет место определенная коллизия с упомянутым выше абзацем первым части 4 статьи 29.2 Закона № 184-Ф3, где фактически безапелляционно определено, что плановые проверки проводятся органами контроля (надзора) совместно. То есть данное обстоятельство исключает проведение проверки каким-либо контрольно-надзорным органов в одиночку, что далеко не всегда оправдано. А с точки зрения абзаца третьего этой же части статьи прокурор по итогам рассмотрения проекта плана уполномочен лишь вносить предложения о проведении совместных проверок, что явно диссонирует с приведенным выше императивом. Таким образом, на наш взгляд, имеющуюся коллизию можно устранить, определив, что проверки органами контроля (надзора) проводятся совместно, если это решает прокурор в ранге обозначенного законодателем координатора по результатам изучения проектов планов соответствующих органов. При этом, по нашему мнению, речь должна идти о внесении прокурором (а не прокуратурой) не предложений, а требований. 
Вторая составляющая координационной миссии прокуратуры - это согласующая роль при проведении внеплановых проверок, которую мы относим к предмету надзора за исполнением законов (общему надзору). В соответствии с частью 5 статьи 29.2 Закона № 184-ФЗ внеплановые проверки деятельности органов государственной власти субъектов Российской Федерации и должностных лиц таких органов проводятся органами государственного контроля (надзора) по согласованию с прокуратурой субъекта Российской Федерации. Основанием для них могут служить обращения граждан, организаций и полученной от государственных органов, органов местного самоуправления информации о фактах нарушений законодательства Российской Федерации, влекущих или могущих повлечь возникновение чрезвычайных ситуаций, угрозу жизни и здоровью граждан, а также массовые нарушения прав граждан.

Обращает на себя внимание то обстоятельство, что законодатель не принял во внимание как основание информацию о фактах нарушения регионального законодательства. Этим, по сути, нивелируется как возможность проведения проверок контрольно-надзорными органами, так и надзорная роль прокурора в части применения согласовательных полномочий. Ведь при дословном истолковании «буквы закона» (а иное можно рассматривать лишь как циничное игнорирование его) внеплановые проверки проводятся только по фактам нарушения федерального законодательства, влекущих или могущих повлечь возникновение чрезвычайных ситуаций, угрозу жизни и здоровью граждан, а также массовые нарушения прав граждан, и исключительно при наличии согласия прокурора. Значит, логически получается, что все остальные случаи обращения граждан и иных лиц в связи с реальными и предполагаемыми нарушениями со стороны органов государственной власти субъектов Российской Федерации и должностных лиц этих органов не относятся к основаниям внеплановых проверок. А это сразу заставляет вспомнить статью 33 Конституции Российской Федерации, согласно которой граждане России имеют право обращаться лично, а также направлять индивидуальные и коллективные обращения в государственные органы. И этому праву должна корреспондировать обязанность, заключающаяся в проверке доводов, изложенных в соответствующем обращении, исходя из компетенции соответствующего государственного органа. То есть возникает коллизия еще и с Федеральным законом от 02.05.2006 № 59-Ф3 «О порядке рассмотрения обращений граждан Российской Федерации» [12], предписывающим уделять каждому обращению надлежащее внимание с учетом компетенции конкретного органа.
Безусловно, можно рассматривать в качестве определенного компенсатора абзац второй части 5 статьи 29.2 Закона № 184-ФЗ, согласно которому внеплановые проверки могут проводиться также на основании требования Генерального прокурора Российской Федерации, прокурора субъекта Российской Федерации о проведении внеплановой проверки в рамках надзора за исполнением законов по поступившим в органы прокуратуры материалам и обращениям (что предусмотрено также пунктом 1 статьи 22 Закона о прокуратуре). Однако граждане и иные лица далеко не всегда обращаются непосредственно в прокуратуру, а орган государственного контроля (надзора), в который поступило первоначально обращение, может и не разъяснить заявителю этого. Таким образом, по нашему мнению, налицо недоработка законодателя, который явно сузил предмет контрольно-надзорной деятельности применительно к проведению внеплановых проверок.

В части 8 статьи 29.2 Закона № 184-ФЗ оговаривается, что положения указанной статьи не применяются в случаях, если федеральными законами установлен иной порядок организации и проведения контроля (надзора) за деятельностью органов государственной власти субъектов Российской Федерации и должностных лиц этих органов, а также к мероприятиям по контролю (надзору), проводимым должностными лицами органов федеральной службы безопасности. Данное обстоятельство требует четкого представления прокурорами о соответствующих органах, их компетенции.

В силу части 7 статьи 29.2 Закона № 184-Ф3 информация о плановых и внеплановых проверках органов государственной власти субъектов Российской Федерации и должностных лиц таких органов, об их результатах и о принятых мерах по пресечению и (или) устранению последствий выявленных нарушений подлежит внесению в единый реестр проверок, который ведется в соответствии с утвержденными постановлением Правительства Российской Федерации от 28.04.2015 № 415 Правилами формирования и ведения единого реестра проверок [13], а оператором указанного реестра является согласно части 1 статьи 13.3 Закона № 294-Ф3 Генеральная прокуратура Российской Федерации, что позволяет отнести указанную работу к упомянутому выше самостоятельному участку внешнефункциональной деятельности прокуратуры - государственному учету.

Таким образом, подводя итог проведенному исследованию новелл, отметим, что законодателю не удалось сформулировать оптимальный алгоритм деятельности органов государственного контроля (надзора) в рассмотренной сфере, что очевидно потребует внесения в статью 29.2 Закона № 184-ФЗ необходимых корректив. 


\section{Библиография:}

1. Федеральный закон от 03.07.2016 № 298-Ф3 «О внесении изменений в главу V Фе-дерального закона «Об общих принципах организации законодательных (представитель-ных) и исполнительных органов государственной власти субъектов Российской Федера-ции» и статью 77 Федерального закона «Об общих принципах организации местного са-моуправления в Российской Федерации»// http://www.pravo.gov.ru. [Электронный ресурс] (дата обращения: 07.07.2016).

2. СЗ РФ. - 1999. - № 42. - Ст. 5005 (с посл. изм.).

3. Справочно-информационная система «КонсультантПлюс».

4. Федеральный закон от 26.12.2008 № 294-Ф3 «0 защите прав юридических лиц и индивидуальных предпринимателей при осуществлении государственного контроля (над-зора) и муниципального контроля» (далее - Закон № 294-ФЗ) // СЗ РФ. 2008. № 52 (ч. 1). Ст. 6249 (с посл. изм.).

5. Федеральный закон от 06.10.2003 № 131-Ф3 «Об общих принципах организации местного самоуправления в Российской Федерации» (далее - Закон № 131-ФЗ) // СЗ РФ. 2003. № 40. Ст. 3822 (с посл. изм.).

6. Винокуров А.Ю. Законодательные новеллы о прокуратуре: достоинства и недос-татки // Lex russica. - 2014. № 8. - С. 958-964.

7. СЗ РФ. - 1995. - № 47. - Ст. 4472 (с посл. изм.).

8. Винокуров А.Ю. Надзор за соответствием правовых актов Конституции Россий-ской Федерации: предмет и пределы // Российская юстиция. - 2012. - № 10. - С. 41-44.

9. Винокуров А.Ю. Проблемы разграничения компетенции прокуроров и органов го-сударственного контроля (надзора) в контексте статьи 77 Федерального закона «Об общих принципах организации местного самоуправления в Российской Федерации» // Актуаль-ные проблемы российского права. - 2014. - № 8. - С. $1626-1631$.

10. СЗ РФ. - 2011. - № 28. - Ст. 4217 (с посл. изм.).

11. Винокуров А.Ю. Государственный учет как самостоятельное направление (уча-сток) деятельности прокуратуры Российской Федерации // Административное и муници-пальное право. - 2011. - № 3. - С. 74-76.

12. СЗ РФ. - 2006. - № 19. - Ст. 2060 (с посл. изм.).

13. СЗ РФ. - 2015. - № 19. - Ст. 2825.

\section{References (transliterated):}

1. Federal'nyi zakon ot 03.07.2016 № 298-FZ «O vnesenii izmenenii v glavu V Fe-deral'nogo zakona «Ob obshchikh printsipakh organizatsii zakonodatel'nykh (predstavitel'-nykh) i ispolnitel'nykh organov gosudarstvennoi vlasti sub"ektov Rossiiskoi Federa-tsii» i stat'yu 77 Federal'nogo zakona «Ob obshchikh printsipakh organizatsii mestnogo sa-moupravleniya v Rossiiskoi Federatsii»// http://www.pravo.gov.ru. [Elektronnyi resurs] (data obrashcheniya: 07.07.2016).

2. SZ RF. - 1999. - № 42. - St. 5005 (s posl. izm.).

3. Spravochno-informatsionnaya sistema «Konsul'tantPlyus».

4. Federal'nyi zakon ot 26.12.2008 № 294-FZ «0 zashchite prav yuridicheskikh lits i individual'nykh predprinimatelei pri osushchestvlenii gosudarstvennogo kontrolya (nad-zora) i munitsipal'nogo kontrolya» (dalee - Zakon № 294-FZ) // SZ RF. 2008. № 52 (ch. 1). St. 6249 (s posl. izm.).

5. Federal'nyi zakon ot 06.10 .2003 № 131-FZ «Ob obshchikh printsipakh organizatsii mestnogo samoupravleniya v Rossiiskoi Federatsii» (dalee - Zakon № 131-FZ) // SZ RF. 2003. № 40. St. 3822 (s posl. izm.).

6. Vinokurov A.Yu. Zakonodatel'nye novelly o prokurature: dostoinstva i nedos-tatki // Lex russica. - 2014. - № 8. S. 958-964.

7. SZ RF. - 1995. - № 47. - St. 4472 (s posl. izm.).

8. Vinokurov A.Yu. Nadzor za sootvetstviem pravovykh aktov Konstitutsii Rossii-skoi Federatsii: predmet i predely // Rossiiskaya yustitsiya. - 2012. - № 10. - S. 41-44.

9. Vinokurov A.Yu. Problemy razgranicheniya kompetentsii prokurorov i organov go-sudarstvennogo kontrolya (nadzora) $\mathrm{v}$ kontekste stat'i 77 Federal'nogo zakona «Ob obshchikh printsipakh organizatsii mestnogo samoupravleniya v Rossiiskoi Federatsii» // Aktual'-nye problemy rossiiskogo prava. - 2014. - № 8. - S. 1626-1631.

10. SZ RF. - 2011. - № 28. - St. 4217 (s posl. izm.).

11. Vinokurov A.Yu. Gosudarstvennyi uchet kak samostoyatel'noe napravlenie (ucha-stok) deyatel'nosti prokuratury Rossiiskoi Federatsii // Administrativnoe i munitsi-pal'noe pravo. - 2011. - № 3. - S. 74-76.

12. SZ RF. - 2006. - № 19. - St. 2060 (s posl. izm.).

13. SZ RF. - 2015. - № 19. - St. 2825. 